\title{
SOBRE EL ORIGEN DE LAS FÓRMULAS HONORÍFICAS CON EL SUFIJO -ISIMO
}

Andrzej Zieliński*

\begin{abstract}
The purpose of this paper is to explore and analyze diachronically honorific expressions with the superlative suffix -ísimo, whose origin corresponds to a pattern of lexicalization that reflects the interpersonal relations of the strongly stratified society of that time. In fact, the feudal pyramid, established since the fifth century AD, which places the highest classes at the highest point, is in clear correspondence with the conceptual metaphor "more is above". Through analysis of a relatively large corpus of Latin $\left(5^{\text {th }}-12^{\text {th }}\right.$ centuries) and Spanish $\left(13^{\text {th }}\right.$ $16^{\text {th }}$ centuries) texts, I will try to find the main reasons that came to determine its use in the Castilian language.
\end{abstract}

Keywords: honorific expressions, superlative suffix, lexicalization pattern, feudalism.

Palabras clave: fórmulas honoríficas, sufijo superlativo, patrón de lexicalización, feudalismo.

\section{1.}

\section{Introducción}

El objetivo de este estudio es el análisis del origen de las fórmulas honoríficas con el sufijo superlativo -ísimo, inexistentes en el latín clásico y cuyas primeras manifestaciones en español se registran

\footnotetext{
* Uniwersytet Jagielloński, Wydział Filologiczny, Instytut Filologii Romańskiej, Zakład Filologii Hiszpańskiej, Al. Mickiewicza 9A, 31-120 Kraków, Polonia, andrzej.zielinski@uj.edu.pl.
} 
a finales del siglo XV (1a-b), centuria en la que, según Lapesa (1970), en la sociedad renacentista española prevalece la moda por lo ceremonial:

(1) a. Serenissimo rey, nuestro muy caro e muy amado sobrino. Entendido hauemos que la barcha de Manoli, patroneada por Francisco Gambacurta, con banderas vuestras, estos passados dias, tomo en la mar sessenta y vna pieça de chamelotos e vna bala de alcatiffas de Pelegrino Orlandis (Anónimo, Fernando al rey Fernando de Nápoles, 1495).

b. Al serenissimo principe don Ferrando, por la gratia de Dios rey de Sicilia de aqua Far, etc., nuestro muy caro e muy amado hermano. Serenissimo rey, nuestro muy caro e muy amado hermano (Anónimo, Fernando dispone se acepten en las cuentas del tesorero general, 1482).

La problemática que proponemos abordar en las páginas siguientes se debe a la visible falta de los estudios de la sociopragmática diacrónica que se dediquen exclusivamente a este elemento honorífico. Por esta razón, proponemos analizar su origen y sus primeras manifestaciones en español.

Vamos a partir de la hipótesis, que a lo largo de este estudio procuraremos demostrar, de que su origen y desarrollo se debe a la imposición del feudalismo en el siglo $\mathrm{V}$, cuya escala social vertical coincide con la escala de cuantificación gracias a la metáfora conceptual MÁS ES ARRIBA. Para ello, con la ayuda del corpus de los textos latinos (siglos V-IX) procedentes de BREPOLIS -y españoles (siglos XV-XVI) - elaborados a base de la búsqueda de CORDE, intentaremos hallar las principales razones que vinieron a determinar su empleo en la lengua española.

La estructura del presente estudio es la siguiente: en primer lugar, vamos a delimitar la fórmula honorífica con el sufijo sintético, así como presentaremos sus principales rasgos $(\$ 1)$. A continuación $(\$ 2)$, procederemos a estudiar su procedencia y sus primeras manifestaciones en español ( $\$ 3)$. Terminan este estudio breves conclusiones $(\$ 4)$. 


\section{2.}

\section{En torno a la fórmula honorífica con el sufijo superlativo}

Por fórmulas honoríficas con el sufijo superlativo entendemos expresiones nominales de la deixis social, previamente lexicalizadas 1 , que se enclavan en el marco discursivo de las relaciones interpersonales establecidas para un determinado acto de habla entre sus participantes y que contribuyen a proporcionar el estatus social del destinatario y del referente $(2 a-b)$ :

(2) a. Yo Xristoval del Barrio, escrivano de su magestad por comisyón que Truxe del Ilustrísimo señor conde de Tendilla, capitán general de este rreino de Granada (Anónimo, Inventario de bienes moriscos del Reino de Granada, 1562).

b. Al excelentísimo Don Juan de Austria. En tanta multitud de libros, excelentísimo señor (Santa Cruz de Dueñas, Floresta española, 1574).

c. Señor excelentíssimo, sereníssimo (sea lo que fuere) (Gracián, El Criticón, 1657).

Nótese que, desde la perspectiva estrictamente morfosintáctica, las fórmulas en cuestión se acomodan a la clase de adjetivos intensionales en el sentido de que el valor honorífico que los caracteriza se desprende únicamente de su anteposición (2a-b). Su posposición involucra siempre la reinterpretación del adjetivo en conformidad con el principio de composicionalidad, de modo que en su lectura se envuelve con frecuencia el valor irónico (2c) (cfr. Zieliński, 2017: 74-79).

Debido a su carácter nominal, estas pueden aparecer, por una parte, en forma de vocativo con la cual se desenvuelve la función

1 Dado un abanico de procesos que abarca el término de lexicalización, en este estudio por lexicalización vamos a entender, siguiendo a Blank (2001: 1603), el proceso de la creación de un lexema meramente convencionalizado. 
apelativa, convirtiéndose así en mero elemento extraoracional (2b), que sirve para llamar la atención del destinatario (Daniel, Spencer, 2009: 632; Sonnenhauser, Azziz Hanna, 2010: XII-XVI), identificándolo (Espinal, 2010: 111).

Por la otra, puede adquirir el papel denominativo (Zieliński, 2015b: 13), como mero honorífico referencial, con el que se desenvuelve bajo diferentes empleos sintácticos (2a). Con esta función, desde las primeras documentaciones en español está precedido por algún determinante.

El carácter meramente nominal del honorífico en cuestión hace que la fórmula se someta a numerosas fluctuaciones tanto semánticas como socio-pragmáticas. Esto es así, ya que, como bien se sabe, el léxico resulta más reconocible por parte de los hablantes y, consecuentemente, puede ser más fácilmente alterado por ellos según determinadas necesidades comunicativas con el objetivo de obtener algún efecto perloctivo.

(3) a. Al rey don Fernando, fijo bastardo del rey don Alfonso de Aragon, ayudo mucho en este caso un casamiento que avia fecho de una fijasuya con un sobrino del Papa Pio, donde asy fue que muerto el ylustrissimo rey don Alfonso de Aragon (Anónimo, Crónica de Enrique IV de Castilla, ca. 1481).

b. Yo Xristoval del Barrio, escrivano de su magestad por comisyón que truxe del Ilustrísimo señor conde de Tendilla (Anónimo, Inventario de bienes moriscos del Reino de Granada, 1562).

c. Prohibimos y defendemos, que ninguna persona pueda llamar Señoría Ilustrísima ni Reverendísima de palabra ni por escrito á otra alguna de qualquier estado ó condicion, grado y oficio que tenga, por grande y preeminente que sea, excepto á los Cardenales, que no es nuestra voluntad que sean comprehendidos en nuestra ley: asimismo, por la autoridad y grandeza de la dignidad del Arzobispo de Toledo, mandamos, que todos sean obligados á llamarle Señoría ilustrísima, por ser 
Primado de las Españas, aunque no sea Cardenal; y permitimos, que al Presidente del nuestro Consejo, y al Presidente del de Aragon, y al Inquisidor general se les pueda llamar Señoría Ilustrísima (Pragmática de 1630, NRLE, libro VI, título XII, ley I, $\$ 10)$.

$Y$, en efecto, si bien las primeras documentaciones españolas aluden al referente regio ( $3 a$ ), a medida que ganan la frecuencia de empleo en el español áureo, las fórmulas con el superlativo sintético van bajando poco a poco de la escala social llegando a denotar, en el último instante, al estamento privilegiado (3b) (Zieliński, 2015b; 2016; 2017). No obstante, no llegó a descender de la escala más abajo, como ocurrió con el pronombre vos (cfr. Moreno, 2002; Bentivoglio, 2003), dado que su empleo vino altamente restringido con varias pragmáticas que ciñen los tratamientos en cuestión tan solo a los Grandes y los títulos de España (3c).

El movimiento descendente que observamos apunta al cambio desde arriba defendido por Labov (2001: 273-274) conforme con quien la extensión de un elemento lingüístico hacia capas sociales más bajas se lleva a cabo por el prestigio abierto, asociado con el deseo de ascender a la clase social más alta, cuyos títulos y tratamientos otorgados constituyen su capital simbólico y social más representativo (Bourdieu, 1980).

\section{3. \\ Origen}

Resulta sumamente interesante que las fórmulas honoríficas que constituyen el objetivo de este estudio no están documentadas en textos del latín clásico, en el que expresiones adjetivas en superlativo denotaban afecto del referente por el emisor (Dickey, 2002: 133-148). Entre ellas, hallamos CARISSIME ('queridísimo' o 'el más querido'), DULCISSIME ('dulcísimo’ 
o 'el más dulce'), OPTIME ('el mejor'), etc. Nótese que todas se caracterizan por expresar una valoración meramente subjetiva, altamente ambigua semánticamente, ya que admiten valores del superlativo absoluto como el relativo (4a) y cumplen, al mismo tiempo, la máxima de generosidad de Leech (1983: 133-134):

(4) a. illi viri optimi de cohorte istius recuperatores non de absolvendo Apronio deliberarent (M. Tullius Cicero, In C. Uerrem orationes, 3, 31).

['aquellos prohombres, recuperadores de la cohorte de él, no deliberarían acerca de la absolución de Apronio']

b. Gregorius sereno episcopo anconitano uir reuerentissimus (Gregorius Magnus, Registrum epistularum, 8,3 , ca. s. VII).

['Gregorio, hombre reverendísimo, al apacible obispo de Ancona']

Su suerte se vio profundamente vinculada al sufijo superlativo -ISSIMUS, de modo que, con la paulatina desaparición de este, las antiguas expresiones de afecto pierden la fuerza ilocutiva, de tal manera que poseen un valor más débil que el de las fórmulas en grado positivo (Dickey, 2002: 135-137). Con ello podríamos llegar a opinar erróneamente que las expresiones se vuelven obsoletas y desaparecen completamente con la caída del sufijo superlativo del habla vulgar (Väänänen, 1985: 208-209; Herman, 1997: 78). No obstante, nuestra investigación en BREPOLIS hace hincapié en que a partir del siglo $\mathrm{V}$ las fórmulas de tratamiento con el sufijo superlativo vuelven a aparecer y ganan. Sin embargo, ya no designan lazos de camaradería como en latín clásico (4a), sino que llegan a codificar puestos sociales o eclesiásticos elevados, de modo que su empleo viene a ser restringido al referente de la clase social más alta de la sociedad feudal en vías de desarrollo (4b).

Las fórmulas que surgen en los albores del feudalismo se corresponden, en principio, con el modelo formal de las expresio- 
nes de camaradería del latín clásico. No obstante, a diferencia de las expresiones del latín clásico, de aquellas emana únicamente el valor del superlativo relativo con el cual se individualiza (Sánchez López, 2006: 77-78) al referente en el acto de habla, recalcando así una de sus propiedades en grado más elevado, por encima de otros participantes del acto de habla (5). Prueba de ello lo constituye el epitafio de Fernando III el Santo de la catedral de Sevilla en el que los atributos latinos en grado superlativo FIDELLISSIMUS, PATIENTISSIMUS, HUMILISSIMUS fueron traducidos al castellano con la estructura analítica: "el más leal, el más sofrido y el más omildoso" (Zieliński, 2015a: 1160 n. 5):

(5) In synodo aurilianense, quam inuictissimus rex Chlotueus fieri supplicauit, sic decretum est (Anónimo, Concilium Turonense, 189, 411, ca. 567).

['En el Sínodo Aurelianense, que fue solicitado por el invictísimo rey Clodoveo, así se decretó’]

Así pues, con su empleo se suplen satisfactoriamente dos máximas de Leech (1983: 132-139) que garantizan su éxito en épocas posteriores. Por una parte, el emisor se muestra generoso, visto que otorga cualidades en grado superlativo al emisor. Por la otra, se desfocaliza a sí mismo, dado que su lectura implica la ausencia de dichas cualidades en este, inscribiéndose en la máxima de modestia (Zieliński, 2017). De hecho, según el planteamiento de Dihle (1952: 173), la observable actitud de humildad que subyace en la lectura de la fórmula en cuestión, fue impuesta por el cristianismo y contribuyó a la creación de nuevas fórmulas deferenciales que surgen precisamente en los albores del feudalismo.

Además, su empleo se corresponde con el patrón de lexicalización de Talmy (1985) en el que tanto la posición social elevada que ocupa el referente en la sociedad feudal, así como el valor superlativo relativo, con ayuda de la metáfora MÁS ES ARRIBA, coinciden en el mismo punto de la escala vertical (Zieliński, 2015b; 2017). Eso, a su vez, puede aclararnos por qué todos los 
ejemplos latinos 2 (6a-b) y los primeros españoles (6c-d) aluden únicamente al referente del estamento más privilegiado sea secular sea eclesiástico, situado en la pirámide social feudal por encima de otros grupos:

(6) a. Ego enim, religiosissime imperator, te cum ueram pacem requiro, quae non sit uerbis conposita interna dispositione fallaciae (Anónimo, Epistulae ad Luciferum Calaritanum et alios, ca. s. V).

['Yo, pues, religiosísimo emperador, imploro contigo la verdadera paz, que no sea construida mediante palabras con una disposición interna de engaño']

b. Domino reuerendissimo et pontificali honore laudabiliter decorato constantio papae uenerandus (Anónimo, Epistulae aeui Merouingici - Ad Constantium episcopum auct. Uenerando, ca. s. VII).

['Al señor reverendísimo y laudablemente dotado de honor pontificial, el papa Constancio, Venerando']

c. Santísimo y Beatísimo Padre: Entre todos aquellos que hasta nuestros tiempos han escrito materias espirituales que yo haya visto, se podrá afirmar que no hay alguno que haya escrito libros ni en mayor número ni más escogidos y provechosos que el padre fray Luis de Granada (Barromeo, Carta al papa Gregorio XIII, 1582).

d. El qual casamiento el rey don Enrrique e la reyna tenian prometido e otorgado porque la prinçesa ningunos onores en estos reynos oviese, y el casamiento suyo no se concluyese con el ylustrissimo prinçipe de Aragon, don Fernando, legitimo heredero de grandes reynos e señorios (Anónimo, Crónica de Enrique IV de Castilla, ca. 1481-1482).

2 La misma observación está recalcada por Engelbrecht (1893: 5-33) y O’Brien (1930: 88-157). 
Nótese también que los adjetivos calificativos transformados en honoríficos aluden a las cualidades, sin lugar a dudas, en grado superlativo, inherentemente vinculadas al puesto o rango social que ocupa el referente que le fueron impuestas en el seno de la sociedad feudal, pero cristiana. Así, el papa debe, evidentemente, ser el más santo y el más beato de todos $(6 \mathrm{~b}-\mathrm{c})$ y el rey, definido ya en la Segunda Partida (NRLE), "como comenzamiento et cabeza de otros" debe ser el más sabio de todos y, como defensor de la religión cristiana, es también el más religioso (6a, 6d).

Ahora bien, en opinión de Koch (2008: 58-64), varias fórmulas de tratamiento abstractas (p. ej., CLEMENTIA TUA, PIETAS TUA, etc.) pasan a las lenguas románicas gracias a la implantación de la tradición discursiva ${ }^{3}$ diplomática, de carácter heterogéneo, que gira en torno a la carta — regida por las estrictas normas del Ars dictaminis (Camargo, 1991) -, en el que las fórmulas de tratamiento abstractas aparecen en la parte inicial, denominada Salutatio. Es precisamente en esa parte en la que el emisor debe rigurosamente recalcar la posición social del destinatario (referente) y del emisor ("auto-referencia") con el que pretende suavizar un FTA (ing. Face-threatening act) en términos de Brown, Lewinson (1987: 74-80) que aparece en la parte más abajo. Desde esta perspectiva, parece razonable creer que las fórmulas honoríficas con el sufijo superlativo corrieron la misma suerte.

Y en efecto fue así. De hecho, si nos detenemos en el gráfico 1 (ut infra), elaborado a partir de los datos de Zieliński (2017: 116), vemos que las fórmulas honoríficas que nos interesan están ma-

3 La tradición discursiva "se puede formar en relación a cualquier finalidad de expresión o a cualquier elemento de contenido cuya repetición establece un lazo entre actualización y tradición; cualquier relación que se puede establecer semióticamente entre dos elementos de tradición (actos de enunciación o elementos referenciales) que evocan una determinada forma textual o determinados elementos lingüísticos empleados" (Kabatek, 2006: 157). 
yoritariamente documentadas, en todas las épocas, en la tradición diplomática latina, en la que sirven para marcar la posición social elevada del destinatario (7a):

(7) a. Explere uerbis, excellentissime fili, non ualeo, quantum tuo opere, tua uita delector (Gregorius Magnus, Registrum epistularum, 9, 229, s. VII).

['No soy capaz, excelentísimo hijo, de expresar con palabras cuánto me deleito con tu obra, con tu vida']

b. Noverit beatitudo vestra, excellentissime domine, quia domnus Invictissimus imperator non semel sed sepe mihi praecepit (Petrus Damiani, Epistulae, 26, ca s. XI).

['que se conozca vuestra bendición, excelentísimo señor, porque el señor invictísimo emperador me adelantó no solo una vez, sino a menudo']

c. In synodo aurilianense, quam inuictissimus rex Chlotueus fieri supplicauit, sic decretum est (Anónimo, Concilium Turonense, 189, 411 a. 567).

['En el Sínodo Aurelianense, que fue solicitado por el invictísimo rey Clodoveo, así se decretó']

d. ANNO SEPTIMO REGNI ADEFONSI REGIS HISPANORVM, FILII RAYMVNDI COMITIS ET SERENISSIME REGINE DOMNE VRRACE (Anónimo, Chronica Hispana saeculi XII, 1, 33, 1). ['en) el año séptimo del reinado de Alfonso, rey de los españoles, hijo del conde Raimundo y de la serenísima reina doña Urraca']

Amén de ello, el gráfico 1 destaca que, además del género diplomático, las fórmulas honoríficas con el sufijo superlativo se emplean en el género historiográfico (7c), entendiendo por este una tradición discursiva bastante amplia que narra grosso modo acontecimientos pasados y prescinde, en gran medida, de elementos ficticios. 


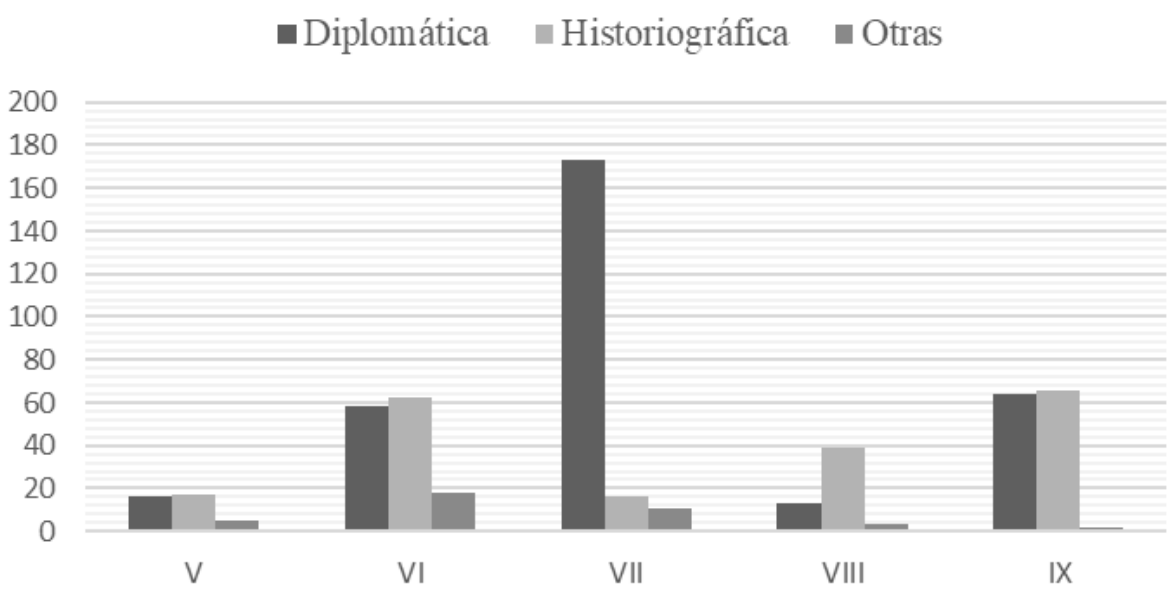

Gráfico 1. Distribución de las fórmulas de tratamiento con -ISSIMUS

Al parecer, estos son precisamente dos canales discursivos de transición de las expresiones honoríficas con el sufijo superlativo al español ( $7 b-d)$.

\section{4. \\ Primeras manifestaciones en español}

Los primeros ejemplos de las fórmulas honoríficas con el sufijo superlativo en el español del cuatrocientos están registrados, únicamente, en el género diplomático $(8 \mathrm{a}-\mathrm{b})$ y, luego, historiográfico (8c). Es precisamente en la rica correspondencia diplomática entre los Reyes Católicos y los virreyes del Reino de Nápoles donde registramos las primeras manifestaciones de la fórmula honorífica:

(8) a. Serenissimo rey, nuestro muy caro e muy amado sobrino (Anónimo, Fernando al rey Fernando de Nápoles, 1495).

b. Muy ylustrissima Infante e corona de las casadas e Condesa (Torre, Libro de las veynte cartas, ca. 1449). 
c. De la muerte de don Pero Giron, maestre de Calatrava, e del gran miraglo que en esto Nuestro Señor demostro por la ylustrissima prinçessa doña Ysabel; e de la cayda de Juan de Valençuela, prior de la orden de Sant Juan, e de muchas cossas acaesçidas de que grandes escandalos se siguieron (Anónimo, Crónica de Enrique IV de Castilla, 1454-1474).

d. Per parte del Illustrissimo e excellentissimo segnor nostro (Anónimo, Grida viscontea dopo la vittoria di Borgoforte, 1398, OVI).

La constante correspondencia diplomática entre la Corona y, primero, el Reino de Nápoles y, luego, el papa español Alejandro VI permite la imposición del castellano en lugar del latín empleado según las pautas de Ars dictaminis en el género diplomático. Sin lugar a dudas, su presencia en italiano (8d) - que por aquella época adquiere mucho prestigio (Terlingen, 1943: 41-47) - contribuyó a su fulminante idiomatización en castellano.

Además, su tardía imposición en el español de finales del cuatrocientos debe verse asociada con la suerte del sufijo superlativo, que justamente por aquel entonces pierde sus restricciones distribucionales, asociadas hasta entonces con el lenguaje eclesiástico, de modo que por influencia italiana empieza a ser portador sociolingüístico de la clase social alta. Lo comprobamos en las palabras de la Dueña Dolorida con las que Cervantes quiere poner en ridículo el habla italianizante del estamento superior (9):

(9) Confiada estoy, señor poderosísimo, hermosísima señora y discretísimos circunstantes, que ha de hallar mi cuitísima en vuestros valerosísimos pechos acogimiento, no menos plácido que generoso y doloroso (Cervantes, Quijote, 1605).

Por último, es también entonces cuando se observa un abrupto cambio de la conceptualización del término de cortesía. Si bien a lo largo de la Edad Media denotaba cualidades internas de saber comportarse moralmente de un noble, el concepto va exteriori- 
zándose, llegando a focalizar lo correcto en la forma de parecer de un individuo, de modo que el término viene a englobar un comportamiento meramente superfluo, pero adecuado en consonancia con ciertas pautas impuestas por la sociedad. Entra en juego, por lo tanto, el concepto de imagen (ing. face), reivindicado por Goffman (1967: 5-6), esto es, la imagen social que uno tiene o quiere tener de sí mismo en el seno de la sociedad a la que pertenece.

(10) No se puede hablar al más humilde del populacho sin bostezarle todos los títulos de honor, y entre ellos se tratan de señores caballeros (Antoine de Brunel, Voyage d'Espagne curieux, historique et politique. Fait en l’année 1655, apud Díez Borque, 1990: 119).

Prueba de ello lo constituye el carácter ceremonioso que Lapesa atribuye a la sociedad española renacentista en cuya vertiente lingüística se encuentra un rico abanico de las fórmulas de tratamiento inexistentes, incluidas las con el sufijo superlativo -ísimo.

\section{5. \\ Conclusiones}

El presente estudio pone de relieve que el origen de las fórmulas honoríficas con el sufijo superlativo se corresponde con el patrón de lexicalización, reflejo de las relaciones interpersonales de la sociedad fuertemente estamental de la época, en el que tanto el grupo más privilegiado de la sociedad feudal como el valor del superlativo relativo, proveniente del sufijo -ísimo - por la actuación de la metáfora conceptual MÁS ES ARRIBA-, convergen satisfactoriamente en una misma ubicación en la escala vertical.

Su filiación al español debe verse inherentemente vinculada desde el principio a dos tradiciones discursivas: la diplomática y la historiográfica, que se caracterizan por la distancia comunicativa. 
Este es el canal de transición a través del cual entran las fórmulas en cuestión en el español del cuatrocientos.

Y, por último, su tardía aparición en la lengua española del cuatrocientos recae satisfactoriamente en el suelo abonado por los gustos ceremoniosos de la sociedad de entonces.

\section{Bibliografía}

Bentivoglio, P. (2003): "Spanish forms of address in the sixteenth century". En: I. Taavitsainen, A. H. Jucker (eds.), Diachronic Perspectives on Address Term Systems. Amsterdam/Philadelphia: John Benjamins Publishing, 177-191.

Blank, A. (2001): "Pathways of lexicalization”. En: M. Haspelmath, E. König, W. Oesterreiche, W. Raible (eds.), Language Typology and Language Universals. Berlin/New York: De Gruyter, 1596-1608.

Bourdieu, P. (1980), "Le Capital social". Actes de la recherche en sciences sociales 31: 2-3.

BREPOLIS: Brepolis Publishers (online), Library of Latin texts, http://www. brepolis.net/index.html [15.06.2017].

Brown, P., Levinson, S. C. (1987): Politeness: Some Universals in Language Usage. Cambridge/New York: Cambridge University Press.

Camargo, M. (1991): Ars dictaminis - ars dictandi. Typologie des sources du Moyen Age occidental. Turnhout: Brepols.

CORDE: Real Academia Española (online), Corpus diacrónico del español, http://www.rae.es [15.06.2017].

Daniel, M., Spencer, A. (2009): "The Vocative - An Outliner Case”. En: A. Malchukov, A. Spencer (eds.), The Oxford Handbook of Case. Oxford/New York: Oxford University Press, 626-634.

Dickey, E. (2002): Latin Forms of Address: From Plautus to Apuleius. Oxford/ New York: Oxford University Press.

Díez Borque, J. M. (1990): La vida española en el Siglo de Oro según los extranjeros. Barcelona: Ediciones Serbal.

Dihle, A. (1952): "Antike höflichkeit und christische Demut". Studi italiani di filologia classica 26: 196-190.

Engelbrecht, A. (1893): Das Titelwesen bei den spätlateinischen Epistolographen. Wien: Brzezowsky. 
Espinal, T. M. (2010): “On the stucture of vocatives”. En: B. Sonnenhauser, P. N. Azziz Hanna (eds.), Vocative! Addressing between system and performance. Berlin/New York: De Gruyter Mouton, 109-132.

Goffman, E. (1967): Interaction Ritual: Essays in Face to Face Behavior. New York: Aldine Transaction.

Herman, J. (1997), El latín vulgar. Barcelona: Ariel.

Kabatek, J. (2006): “Tradiciones discursivas y cambio lingüístico”. En: G. Ciapuscio, K. Jungbluth, D. Kaiser, C. Lopes (eds.), Sincronía y diacronía de tradiciones discursivas en Latinoamérica. Frankfurt am Main/Madrid: Vervuert/Iberoamericana, 151-172.

Koch, P. (2008): “Tradiciones discursivas y cambio lingüístico: el ejemplo del tratamiento 'uestra merced' en español”. En: J. Kabatek (ed.), Sintaxis histórica del español y cambio lingüístico: Nuevas perspectivas desde las Tradiciones Discursivas. Madrid/Frankfurt am Main: Iberoamericana/ Vervuert, 53-88.

Labov, W. (2001): Principles of Linguistic Change Social factors. Oxford: Blackwell.

Lapesa, R. (1970): "Personas gramaticales y tratamientos en español”. Revista de la Universidad de Madrid XIX (74): 141-167.

Leech, G. N. (1983): Principles of Pragmatics. London: Longman.

Moreno, M. C. (2002): "The address system in the Spanish of the Golden Age". Journal of Pragmatics 34: 15-47.

NRLE: Alfonso XII (1805-1829): Novísima recopilación de las leyes de España: Dividida en XII. libros. En que se reforma la Recopilacion publicada por el Señor Don Felipe Il en el año de 1567, reimpresa últimamente en el de 1775: Y se incorporan las pragmáticas, cédulas, decretos, órdenes y resoluciones Reales, y otras providencias no recopiladas y expedidas hasta el de 1804. (Con tres índices generales)/mandada formar por Carlos IV, Reproducción digital del original conservado en la Biblioteca de la Universidad de Sevilla, http:// fama2.us.es/fde/ocr/2006/novisima.RecopilacionT1.pdf [15.06.2017].

O'Brien, M. B. (1930): Titles of Address in Christian Latin Epistolography to 543 A.D. Washington: Catholic University of America.

Sánchez López, C. (2006): El grado de adjetivos y adverbios. Madrid: Arco/ Libros.

Sonnenhauser, B., Azziz Hanna, P. N. (2010): “Introduction: Vocative!”. En: B. Sonnenhauser, P. N. Azziz Hanna (eds.), Vocative! Addressing between system and performance. Berlin/New York: De Gruyter Mouton, I-XXV. 
Talmy, L (1985): “Lexicalization patterns: Semantic structure in lexical forms”. En: T. Shopen (ed.), Language typology and syntactic description. Grammatical Categories and the Lexicon, Vol. III. Cambridge: Cambridge University Press, 57-149.

Terlingen, J. H. (1943): Los italianismos en español: desde la formación del idioma hasta principios del siglo XVII. Amsterdam: NV Noord-Hollandsche Uitgevers Maatschappij.

Väänänen, V. (1985): Introducción al latín vulgar. Madrid: Gredos.

Vossler, K. (1953): Einführung ins Vulgärlatein. München: Hueber.

Wölfflin, E. (1879): Lateinische und Romanische Comparation. Erlangen: Verlag von Andreas Deichert.

Zieliński, A. (2015a): “'Hallé un río grandísimo, digo muy grande’: historia y comportamiento del sufijo -ísimo en español”. En: J. M. García Martín, T. Bastardín Candón, M. Rivas Zancarrón (eds.), Actas del IX Congreso Internacional de Historia de la Lengua Española (Cádiz, 2012). Madrid/ Frankfurt am Main: Iberoamericana/Vervuert, 1157-1170.

Zieliński, A. (2015b): "Sobre el proceso de lexicalización de las fórmulas honoríficas con el sufijo-ís(s)imo en español”. Anuari de Filologia. Estudis de Lingüística 4: 1-18.

Zieliński, A. (2016): “'A la illvstrissima y excelentissima Señora': algunas observaciones sobre los títulos honoríficos con -ís(s)imo en el español áureo". En: J. Wilk-Racięska, A. Szyndler, C. Tatoj (eds.), Relecturas y nuevos horizontes de los estudios hispánicos: lingüística y didáctica de la Lengua Española. Katowice: Wydawnictwo Uniwersytetu Śląskiego, 218-230.

Zieliński, A. (2017): Las fórmulas honoríficas con-ísimo. Contribución a la lexicalización de la deixis social. Frankfurt am Main: Peter Lang. 